\title{
Cardiovascular Diseases' Awareness Among Women in Northern Jordan
}

\author{
Abdulhakeem M Okour ${ }^{1}$, Rami A Saadeh ${ }^{1}$, Neda Redwan ${ }^{1} \&$ Muhammad Faizal Bin A. Ghani ${ }^{2}$ \\ ${ }^{1}$ Department of Public Health and Family Medicine, Faculty of Medicine, Jordan University of Science and \\ Technology, Irbid, Jordan \\ ${ }^{2}$ Department of Educational Management, Planning and Policy, Faculty of Education, University of Malay, Kuala \\ Lumpur, Malaysia \\ Correspondence: Rami Saadeh, Department of Public Health and Family Medicine, Faculty of Medicine, Jordan \\ University of Science and Technology. Irbid, Jordan Tel: 962-79-881-4090. E-mail: Rasaadeh@just.edu.jo
}

Received: January 12, 2019 Accepted: February 15, 2019 Online Published: February 25, 2019

doi:10.5539/gjhs.v11n3p102 URL: https://doi.org/10.5539/gjhs.v11n3p102

\begin{abstract}
Background: Women's awareness of chronic diseases, including cardiovascular diseases, is the cornerstone in promoting women's health. Objectives: To examine the relationship of awareness levels about cardiovascular diseases and their related risk factors with demographic information of Jordanian women.

Methods: A cross-sectional study of 18 years and older women. Scores of awareness were computed for each individual and were divided into 4 quartiles. Logistic regression analysis was used to examine the association of demographic information of participants with mean scores of quartiles. ANOVA analysis was used to compare the mean scores of quartiles.
\end{abstract}

Results: A total of 514 women completed the questionnaire, with a mean age of $35.46( \pm 12.53)$. Current smokers were $6.2 \%$, and $34.6 \%$ had a family history of heart disease. The proportion of diabetes, hypertension, hypercholesterolemia, and overweight/obesity were $15.6 \%, 19.3 \%, 14.4 \%, \& 21.6 \%$ respectively. The mean score for awareness was $12.87( \pm 3.26)$. Women who had lower income and who were at younger age were more likely to score low in awareness.

Conclusion: Women illustrated a fair level of awareness of CVD and its related risk factors. Increasing women awareness of CVD through educational programs, targeted toward women at risk, assists in disease prevention and help to improve treatment plans.

Keywords: women's health, cardiovascular diseases, awareness, Jordan

\section{Introduction}

Cardiovascular diseases (CVD) include diseases of the heart and blood vessels, and vascular diseases of the brain (Aminde et al., 2017; Mozaffarian, 2017). They are responsible for over 19.9 million deaths per year and are the leading causes of death worldwide (Aminde et al., 2017; Mozaffarian, 2017). CVD commonly occurs as the result of a combination of modifiable and non-modifiable risk factor. Modifiable CVD risk factors include hypertension, tobacco use, physical inactivity, alcohol consumption, poor diet, high serum triglycerides, low High - Density Lipoprotein (HDL) cholesterol, abdominal obesity, high serum blood glucose, and insulin resistance/diabetes and non-modifiable risk factors are age, gender, and ethnicity (Aminde et al., 2017; Cobiac et al., 2012; Fahs, Khalife, Malaeb, Iskandarani, \& Salameh, 2017). CVDs continue to rise mainly because preventive measures are inadequate, and rates of modifiable risk factors are increasing at unprecedented levels (Aminde et al., 2017; Fahs et al., 2017). It is widely accepted that a substantial proportion of CVD burden is preventable through reduction of modifiable risk factors. Between $36 \%$ and $63 \%$ of myocardial infarctions and $20 \%$ and $31 \%$ of strokes could be prevented (Fahs et al., 2017).

Lack of awareness of CVD and its risk factors among women was reported in many previous studies (Aminde et al., 2017; Awad \& Al-Nafisi, 2014; Bunker et al., 2003; Fahs et al., 2017; Kaddumukasa et al., 2015; Mukattash et al., 2012; Obembe, Olaogun, Bamikole, Komolafe, \& Odetunde, 2014). The evidence indicates that in women with better awareness of CVD and risk factors, modification of risk factors through change in lifestyle habits and behaviors such as smoking, physical inactivity and obesity has been achieved in higher pace and magnitude, in 
addition to improving attendance to health care services (Cobiac et al., 2012; Ebrahim et al., 2011; Eriksson, Franks, \& Eliasson, 2009; Mozaffarian, 2017). Other studies have reported improved CVD outcomes with better awareness (Alam, Chowdhury, Siddiquee, Ahmed, \& Niessen, 2014; Aminde et al., 2017; Boateng et al., 2017; Choi et al., 2010; Ebrahim et al., 2011; Eriksson et al., 2009).

There is little information reported in the literature on Jordanian women's awareness of CVD and risk factors, while a few studies reported a lack of CVD awareness among Jordanian population in general (Kannel, 2002; Mosca et al., 2006; Oliver-Mcneil \& Artinian, 2002). In 2010, cardiovascular disease was the leading cause of death in Jordan, accounting for $40 \%$ of all deaths in that year [10]. Ammouri et al 2016, reported lack of knowledge regarding the risk of coronary heart disease, particularly among women and young adults (Ammouri et al., 2016). Similarly, Eshah et al 2013, assessed healthy lifestyle behaviors among Jordanian adults, and found that $50 \%$ of the participants had excess weight; $30 \%$ were current smokers; and 33\% reported having a family history of coronary heart disease (Eshah, 2013). It is therefore important that Jordanian women be aware of CVD and its risk factors, which will improve their utilization of health care services, and decrease disease burden (Chen, Lin, \& Lin, 2013; Snider, 1980; Yarger, Decker, Campa, \& Brindis, 2017). The purpose of this study was to assess level of CVD awareness among women in Jordan, and to examine the relationship of awareness levels about cardiovascular diseases and their related risk factors with demographic information of participants.

\section{Methodology}

\subsection{Study Design, Setting and Sample}

This was a descriptive cross-sectional study carried out on women who were 18 years and above. The initial sample included 565 women randomly selected in a systematic approach by selecting every other woman who attended the Jordan University of Science and Technology (JUST) health care center in Irbid city, Jordan. However, the final sample was 514 (90.9\% response rate) women who agreed to participate in the study and had completed the survey. A minimum sample size was determined using PS power and sample size calculator V.3.05 (Dupont \& Plummer, 1998), considering confidence level of $95 \%$ and a 0.04 margin of error, this gave an estimated minimum sample size of 515. The study was approved by the Institutional Review Board (IRB) of JUST.

\subsection{Data Collection}

The questionnaires were distributed to women who agreed to participate in the study. Purpose of the study and study details were described to them, as well as they were reassured about the complete confidentiality of the study. They were also guaranteed by the study team that there would not be any interference with their responses.

\subsection{Measurements and Analysis}

A questionnaire in Arabic language consisting of questions on demographic characteristics and others adapted from the "American Heart Association Women's Heart Disease and Stroke Campaign Task Force Study" (Mosca et al., 2000) to assess the level of knowledge on heart diseases. The questionnaire consisted of two sections; the first section included questions about age, marital status, education level, occupation, monthly family income, presence of chronic diseases, and family history of heart diseases. The second section (see Table 3) included 23 items which measured awareness of heart diseases and related risk factors. These items are close ended questions constructed as true, false, and do not know. Only answers reported as "True" were calculated in the total score for each participant. Thus, the highest possible score was 23; if all answers were correct. Percentages for the number of women who correctly answered questions on heart disease and its risk factors were calculated.

Women's awareness scores were categorized into four levels based on quartiles. The first quartile (Q1) represented the lowest quarter of awareness level; the fourth quartile $(\mathrm{Q} 4)$ represented the highest quarter of awareness. For each group of awareness, we used two-sample t-test or ANOVA to examine differences among the quartiles' means. This approach was used in previous studies (El Ansari, Oskrochi, \& Haghgoo, 2014; Handel \& Fritzsche, 2016; Karmacharya et al., 2017). Logistic regression was used to examine the association of demographic characteristics with scores' quartiles.

The original English language questionnaire was translated to Arabic language, and was translated back to English by independent expert, validated and tested. To test the applicability of the questionnaire, a pilot testing was conducted on 20 women, and accordingly, modifications were made. Internal consistency and reliability was measured by calculating Cronbach's alpha coefficient, which was 0.89 . P - Value less than 0.05 was considered significant and data was analyzed using Statistical Package for Social Science (SPSS) software version 20. The study was approved by the Institutional Review Board of JUST. 


\section{Results}

The characteristics of 514 women who participated in the study are summarized in Table 1 . The age of participants ranged from 18 to 75 years, with a mean age of 35.46 ( \pm 12.53$)$. Most participants were young (under the age of 30 ), well-educated (diploma degree or more) and had a family income between 300 and 500 JD (\$423-\$706) per month.

Table 1. Demographic information of the sample

\begin{tabular}{ll}
\hline Demographic information & Frequency (percentages \%) \\
\hline $18-29$ years old & $211(41.1 \%)$ \\
$30-39$ years old & $101(19.6 \%)$ \\
$40-49$ years old & $120(23.3 \%)$ \\
$50-59$ years old & $64(12.5 \%)$ \\
$\geq 60$ years old & $18(3.5 \%)$ \\
\hline Single & $190(37 \%)$ \\
Married & $297(57.8 \%)$ \\
Divorced & $12(2.3 \%)$ \\
Widow & $15(2.9 \%)$ \\
\hline Illiterate or Primary education & $36(7 \%)$ \\
Secondary education & $120(23.3 \%)$ \\
Diploma degree & $98(19.1 \%)$ \\
Bachelor's degree & $232(45.1 \%)$ \\
Graduate degree & $28(5.4 \%)$ \\
\hline Student & $121(23.5 \%)$ \\
Employed & $161(31.3 \%)$ \\
Unemployed & $202(39.3 \%)$ \\
Retired & $30(5.8 \%)$ \\
\hline Less than 300 JD of monthly income & $128(24.9 \%)$ \\
300-500 JD of monthly income & $196(38.1 \%)$ \\
$501-700$ JD of monthly income & $83(16.1 \%)$ \\
More than 700 JD of monthly income & $107(20.8 \%)$ \\
\hline
\end{tabular}

JD: Jordanian Dinars.

Table 2 demonstrates the prevalence of cardiovascular diseases and risk factors in participants based on what they have reported. All chronic diseases were lower in this sample than the general population, however, smoking was more prevalent.

Table 2. Self-reported prevalence of cardiovascular diseases' risk factors in women

\begin{tabular}{ll}
\hline Self-reported risk factors & Frequency (Percentages \%) \\
\hline Diabetes & $80(15.6 \%)$ \\
High Blood Pressure & $99(19.3 \%)$ \\
High Cholesterol & $74(14.4 \%)$ \\
Overweight or obesity & $111(21.6 \%)$ \\
Non-smoker & $345(67.1 \%)$ \\
Smoker & $32(6.2 \%)$ \\
\hline
\end{tabular}




\begin{tabular}{ll}
\hline Ex-smoker & $7(1.4 \%)$ \\
Passive smoker & $130(25.3 \%)$ \\
Family History & $178(34.6 \%)$ \\
\hline
\end{tabular}

Table 3 shows women's responses to core questions that measured awareness. Mean for correct scores of awareness was $12.87( \pm 3.26)$, which corresponds to $55.9 \%$, and scores ranged from 0 to 23 .

Table 3. Knowledge about Cardiovascular diseases and their related risk factors

\begin{tabular}{|c|c|c|c|}
\hline & Item & $\begin{array}{l}\text { Correct answers } \\
(n=514)\end{array}$ & Percentage $\%$ \\
\hline 1 & Heart disease is the leading cause of death in women Globally. & 125 & 24.3 \\
\hline 2 & $\begin{array}{l}\text { Having family history of heart disease lead to a higher risk of getting heart } \\
\text { disease. }\end{array}$ & 352 & 68.5 \\
\hline 3 & Being overweight lead to higher risk of getting heart disease. & 468 & 91.1 \\
\hline 4 & Having diabetes increase the risk of getting heart disease. & 305 & 59.3 \\
\hline 5 & Having high blood pressure increase the risk of getting heart disease. & 425 & 82.7 \\
\hline 6 & Having high cholesterol lead to a higher risk of getting heart disease. & 428 & 83.3 \\
\hline 7 & Not exercising increases the risk of getting heart disease. & 423 & 82.3 \\
\hline 8 & Smoking can increase the risk of getting heart disease. & 480 & 93.4 \\
\hline 9 & Low levels of estrogen lead to a higher risk of getting heart disease. & 105 & 20.4 \\
\hline 10 & Stress lowers the risk of heart disease. & 71 & 13.8 \\
\hline 11 & High Density Lipoprotein (HDL) is good for the heart. & 99 & 19.3 \\
\hline 12 & Low Density Lipoprotein (LDL) is bad for the heart. & 118 & 23.0 \\
\hline 13 & Eating 2-3 portions of fruit and vegetable daily is beneficial to the heart. & 440 & 85.6 \\
\hline 14 & $\begin{array}{l}\text { Reducing animal products such as meat, whole milk, butter and cream in my diet } \\
\text { lower the risk of getting heart disease. }\end{array}$ & 405 & 78.8 \\
\hline 15 & Increasing sodium or salt in the diet lower my risk of getting heart disease. & 93 & 18.1 \\
\hline 16 & Vegetable oils are healthier to the heart than butter or margarine for cooking. & 433 & 84.2 \\
\hline 17 & If I am overweight, losing weight can lower my chance of getting heart disease. & 439 & 85.4 \\
\hline 18 & Women are more likely to get heart disease after menopause. & 249 & 48.4 \\
\hline 19 & Young women do not get heart disease. & 85 & 16.5 \\
\hline 20 & Hypertension medications should be used for a lifetime. & 303 & 58.9 \\
\hline 21 & Every person with high cholesterol level is given medicine. & 300 & 58.4 \\
\hline 22 & There is nothing I can do to help prevent myself from getting heart disease. & 95 & 18.5 \\
\hline 23 & Heart disease develops gradually over many years & 374 & 72.8 \\
\hline
\end{tabular}

ANOVA analysis revealed a highly significant difference between quartile means $(\mathrm{p}<0.0001)$. Running LSD post - Hoc analysis, all quartiles were significantly different from each other.

Logistic regression analysis revealed that age and income were statistically significant in all quartiles compared to Q4 (Table 4). Younger ages were more likely to score lower (i.e. Q1 - Q3) than elders (above 50). In addition, women with lower incomes were more likely to be in the first two quartiles than to be in Q4. 
Table 4. Relationship of demographic information with scores of awareness

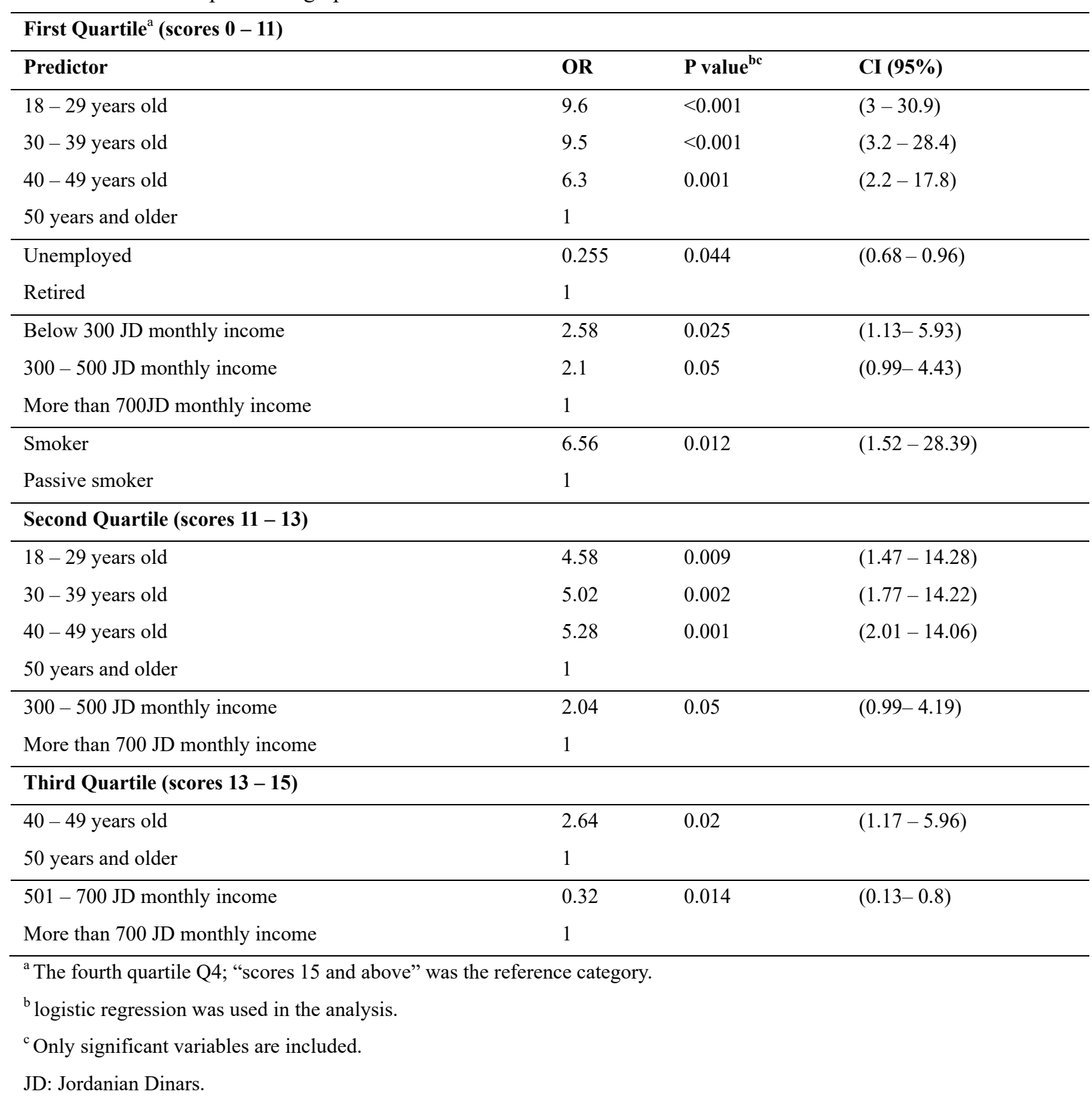

\section{Discussion}

Cardiovascular diseases and their related risk factors are a serious threat to women's health. It increases mortality rates among women and affects women's quality of life for those who survive it and increase the cost of health care system. Understanding risk factors of diseases has advanced the efforts for prevention. Women's awareness of high blood pressure, serum lipids, smoking and other risk factors for developing cardiovascular event, in addition to knowing causes of death is the cornerstone in promoting women's health, and designing preventive strategies and programs for preventing CVD among women (Scuteri et al., 2009). The present study has tackled women's awareness about one of the most challenging diseases in Jordan. Most women considered overweight, high blood pressure, high cholesterol, and smoking as risk factors, while considered losing weight, reducing dietary cholesterol, reducing animal products intake, eating vegetables and fruits daily, and decreasing salt intake as preventive measures against heart disease. However, findings from this study indicated that even educated and employed women lacked awareness of CVD. The level of awareness reported in our study (55.9\%) is based on the score from correctly answering the 23 items used for measuring awareness. This level is similar to or higher than those reported in previous studies (Mosca et al., 2006; Mozaffarian et al., 2016; Oliver-Mcneil \& Artinian, 2002; 
Scuteri et al., 2009), while is lower than others (Giardina et al., 2011; Mosca et al., 2000), specifically for family history, which was recognized by fewer women as a risk factor. It is also fortunate that majority of women had identified some of the major risk factors of CVD (overweight, diabetes, high blood cholesterol, high blood pressure, not exercising, and smoking), which agrees with other studies (Giardina et al., 2011; Munoz et al., 2010). Approximately, $20 \%$ of women in this study were able to identify HDL as a good cholesterol, and $23.0 \%$ identified LDL as a bad cholesterol. These results were similar to a study by Mosca et al. (2000) (Mosca et al., 2000) on American women but higher than a study by Choi et al. (2010) on Korean women who could correctly recognize HDL and LDL effects by only $8 \%$ and $6 \%$ respectively (Choi et al., 2010).

Assessment of awareness was based on quartile partition of scores; an informative method used in previous studies (El Ansari et al., 2014; Handel \& Fritzsche, 2016; Karmacharya et al., 2017), and served the objectives of this study. Quartile approach helped presenting our data in a manageable way, easy to compare based on ascending score groups that has the same weight. ANOVA comparison between scores revealed a significant difference between quartiles. Every quartile was significantly different than the other one, which indicates a high variability in the level of knowledge among participants. Based on analysis of this study, this variability was partially due to demographic factors such as age and income. Age had high impact on the level of awareness among women, indicating that older respondents were more aware than the younger ones. In addition, family income had a high impact on the level of awareness among women. Women from families of lower incomes were less aware (lower scores) than those with higher incomes. Low family income is strongly associated with an increased prevalence of heart disease risk factors and with greater morbidity and mortality among heart disease patients (Bunker et al., 2003). However, none of other demographic characteristics or known risk factors for CVD, such as smoking history, diabetes, and overweight/obesity were related to heart disease awareness levels.

Findings of the current study revealed a major disappointment in women's awareness of CVD. More than $75 \%$ of women were not able to recognize the leading cause of death among women, a worrying result, which may indicate inconsistency in relating pieces of the circulated health education messages, considering the high average (55.9\%) of awareness scored in this study. Lack of awareness about causes of death among women is a global concern reported by many studies (Alm-Roijer, Fridlund, Stagmo, \& Erhardt, 2006; Choi et al., 2010; Hamner \& Wilder, 2008; KS, 2009; Mosca et al., 2006; Scuteri et al., 2009; Valentín Fuster, 2010), and need to be addressed further in future studies.

\subsection{Limitations and Weaknesses of the Study}

There are some limitations to this study. The health perceptions were totally self-reported, a probable bias may have occurred, especially of reporting status of chronic diseases. Not all responses of women received in similar conditions, resulting in some of 'non-response', which could be attributed to women's time inadequacy and/or inconvenient conditions. In addition, sample size was not as expected, but was diminished due to limited resources of this study. The structure of the sample of women participated, although randomly selected, was dominantly represented by women aged less than 50 years old ( $84 \%)$, educated ( $70 \%$ had diploma or higher education), and relatively had good family monthly income ( $75 \%$ higher than $300 \mathrm{JDs})$. This could have caused a restriction in representation. However, the setting of the university health care center might have influenced this structure. Women in other settings (community or non-health related facility) were not included for comparison.

\section{Conclusion}

This is the first study in Jordan that addresses the level of awareness among Jordanian women regarding cardiovascular diseases and their related risk factors in this comprehensive manner. Women illustrated a fair level of awareness of CVD and its related risk factors compared to other studies, however, they lack awareness about the cause of death among women worldwide and in Jordan. Increasing women awareness of CVD through educational programs, targeted toward women at risk, assists in disease prevention and help to improve treatment plans.

The information resulted from this study offer evidence to health policy decision-makers, clinicians, and health care providers to focus on disease prevention, improve treatment plan, and support health educational programs targeted toward women at risk. It is important to place heart disease as a priority in women's health agenda and health care provision.

\section{Acknowledgements}

We would like to thank the staff, nurses, and doctors who facilitate data collection in the health care center of Jordan University of Science and Technology (JUST) in Irbid city, Jordan. 


\section{Competing Interests Statement}

The authors declare that there are no competing or potential conflicts of interest.

\section{References}

Alam, D. S., Chowdhury, M. A., Siddiquee, A. T., Ahmed, S., \& Niessen, L. W. (2014). Awareness and control of hypertension in Bangladesh: follow-up of a hypertensive cohort. BMJ Open, 4(12), e004983. https://doi.org/10.1136/bmjopen-2014-004983

Alm-Roijer, C., Fridlund, B., Stagmo, M., \& Erhardt, L. (2006). Knowing your risk factors for coronary heart disease improves adherence to advice on lifestyle changes and medication. J Cardiovasc Nurs, 21(5), E24-31. https://doi.org/10.1097/00005082-200609000-00015

Aminde, L. N., Takah, N., Ngwasiri, C., Noubiap, J. J., Tindong, M., Dzudie, A., \& Veerman, J. L. (2017). Population awareness of cardiovascular disease and its risk factors in Buea, Cameroon. BMC Public Health, 17(1), 545. https://doi.org/10.1186/s12889-017-4477-3

Ammouri, A. A., Tailakh, A., Isac, C., Kamanyire, J. K., Muliira, J., \& Balachandran, S. (2016). Knowledge of Coronary Heart Disease Risk Factors among a Community Sample in Oman: Pilot study. Sultan Qaboos Univ Med J, 16(2), e189-196. https://doi.org/10.18295/squmj.2016.16.02.009

Awad, A., \& Al-Nafisi, H. (2014). Public knowledge of cardiovascular disease and its risk factors in Kuwait: a cross-sectional survey. BMC Public Health, 14, 1131. https://doi.org/10.1186/1471-2458-14-1131

Boateng, D., Wekesah, F., Browne, J. L., Agyemang, C., Agyei-Baffour, P., Aikins, A. D., . . Klipstein-Grobusch, K. (2017). Knowledge and awareness of and perception towards cardiovascular disease risk in sub-Saharan Africa: A systematic review. PLoS One, 12(12), e0189264. https://doi.org/10.1371/journal.pone.0189264

Bunker, S. J., Colquhoun, D. M., Esler, M. D., Hickie, I. B., Hunt, D., Jelinek, V. M., . . Tonkin, A. M. (2003). "Stress" and coronary heart disease: psychosocial risk factors. Med J Aust, 178(6), 272-276.

Chen, C. C., Lin, Y. J., \& Lin, Y. T. (2013). Awareness and utilization of preventive care services among the elderly under National Health Insurance. Int $J$ Health Care Finance Econ, 13(3-4), $247-260$. https://doi.org/10.1007/s10754-013-9128-3

Choi, E. J., Jekal, Y., Kim, S., Yoo, J. S., Kim, H. S., Oh, E. G., . . Kim, M. J. (2010). Middle-aged women's awareness of cholesterol as a risk factor: results from a national survey of Korean Middle-aged Women's Health Awareness (KomWHA) study. Int $J$ Nurs Stud, 47(4), $452-460$. https://doi.org/10.1016/j.ijnurstu.2009.09.002

Cobiac, L. J., Magnus, A., Lim, S., Barendregt, J. J., Carter, R., \& Vos, T. (2012). Which interventions offer best value for money in primary prevention of cardiovascular disease? PLoS One, 7(7), e41842. https://doi.org/10.1371/journal.pone.0041842

Dupont, W. D., \& Plummer, W. D., Jr. (1998). Power and sample size calculations for studies involving linear regression. Control Clin Trials, 19(6), 589-601. https://doi.org/10.1016/S0197-2456(98)00037-3

Ebrahim, S., Taylor, F., Ward, K., Beswick, A., Burke, M., \& Davey Smith, G. (2011). Multiple risk factor interventions for primary prevention of coronary heart disease. Cochrane Database Syst Rev, (1), Cd001561. https://doi.org/10.1002/14651858.CD001561.pub3

El Ansari, W., Oskrochi, R., \& Haghgoo, G. (2014). Are students' symptoms and health complaints associated with perceived stress at university? Perspectives from the United Kingdom and Egypt. Int J Environ Res Public Health, 11(10), 9981-10002. https://doi.org/10.3390/ijerph111009981

Eriksson, M. K., Franks, P. W., \& Eliasson, M. (2009). A 3-year randomized trial of lifestyle intervention for cardiovascular risk reduction in the primary care setting: the Swedish Bjorknas study. PLoS One, 4(4), e5195. https://doi.org/10.1371/journal.pone.0005195

Eshah, N. F. (2013). Knowledge of stroke and cerebrovascular risk factors among Jordanian adults. J Neurosci Nurs, 45(5), E13-19. https://doi.org/10.1097/JNN.0b013e31829db99f

Fahs, I., Khalife, Z., Malaeb, D., Iskandarani, M., \& Salameh, P. (2017). The Prevalence and Awareness of Cardiovascular Diseases Risk Factors among the Lebanese Population: A Prospective Study Comparing Urban to Rural Populations. Cardiol Res Pract, 2017, 3530902. https://doi.org/10.1155/2017/3530902

Giardina, E. G., Sciacca, R. R., Foody, J. M., D'Onofrio, G., Villablanca, A. C., Leatherwood, S., . . Haynes, S. G. (2011). The DHHS Office on Women's Health Initiative to Improve Women's Heart Health: focus on 
knowledge and awareness among women with cardiometabolic risk factors. $J$ Womens Health (Larchmt), 20(6), 893-900. https://doi.org/10.1089/jwh.2010.2448

Hamner, J., \& Wilder, B. (2008). Knowledge and risk of cardiovascular disease in rural Alabama women. $J$ Am Acad Nurse Pract, 20(6), 333-338. https://doi.org/10.1111/j.1745-7599.2008.00326.x

Handel, M., \& Fritzsche, E. S. (2016). Unskilled but subjectively aware: Metacognitive monitoring ability and respective awareness in low-performing students. Mem Cognit, 44(2), 229-241. https://doi.org/10.3758/s13421-015-0552-0

Kaddumukasa, M., Kayima, J., Kaddumukasa, M. N., Ddumba, E., Mugenyi, L., Pundik, S., . . Katabira, E. (2015). Knowledge, attitudes and perceptions of stroke: a cross-sectional survey in rural and urban Uganda. BMC Res Notes, 8, 819. https://doi.org/10.1186/s13104-015-1820-6

Kannel, W. B. (2002). The Framingham Study: historical insight on the impact of cardiovascular risk factors in men versus women. $J$ Gend Specif Med, 5(2), 27-37.

Karmacharya, B. M., Koju, R. P., LoGerfo, J. P., Chan, K. C., Mokdad, A. H., Shrestha, A., . . Fitzpatrick, A. L. (2017). Awareness, treatment and control of hypertension in Nepal: findings from the Dhulikhel Heart Study. Heart Asia, 9(1), 1-8. https://doi.org/10.1136/heartasia-2016-010766

KS, G. (2009). Risk factors for cardiovascular disease in women: Review. Maturitas, 63, 186-190. https://doi.org/10.1016/j.maturitas.2009.02.014

Mosca, L., Jones, W. K., King, K. B., Ouyang, P., Redberg, R. F., \& Hill, M. N. (2000). Awareness, perception, and knowledge of heart disease risk and prevention among women in the United States. American Heart Association Women's Heart Disease and Stroke Campaign Task Force. Arch Fam Med, 9(6), 506-515. https://doi.org/10.1001/archfami.9.6.506

Mosca, L., Mochari, H., Christian, A., Berra, K., Taubert, K., Mills, T., .. Simpson, S. L. (2006). National study of women's awareness, preventive action, and barriers to cardiovascular health. Circulation, 113(4), 525-534. https://doi.org/10.1161/CIRCULATIONAHA.105.588103

Mozaffarian, D. (2017). Global Scourge of Cardiovascular Disease: Time for Health Care Systems Reform and Precision Population Health. J Am Coll Cardiol, 70(1), 26-28. https://doi.org/10.1016/j.jacc.2017.05.007

Mozaffarian, D., Benjamin, E. J., Go, A. S., Arnett, D. K., Blaha, M. J., Cushman, M., . . Turner, M. B. (2016). Executive Summary: Heart Disease and Stroke Statistics--2016 Update: A Report From the American Heart Association. Circulation, 133(4), 447-454. https://doi.org/10.1161/CIR.0000000000000366

Mukattash, T. L., Shara, M., Jarab, A. S., Al-Azzam, S. I., Almaaytah, A., \& Al Hamarneh, Y. N. (2012). Public knowledge and awareness of cardiovascular disease and its risk factors: a cross-sectional study of 1000 Jordanians. Int J Pharm Pract, 20(6), 367-376. https://doi.org/10.1111/j.2042-7174.2012.00208.x

Munoz, L. R., Etnyre, A., Adams, M., Herbers, S., Witte, A., Horlen, C., . . Jones, M. E. (2010). Awareness of heart disease among female college students. J Womens Health (Larchmt), 19(12), 2253-2259. https://doi.org/10.1089/jwh.2009.1635

Obembe, A. O., Olaogun, M. O., Bamikole, A. A., Komolafe, M. A., \& Odetunde, M. O. (2014). Awareness of risk factors and warning signs of stroke in a Nigeria university. J Stroke Cerebrovasc Dis, 23(4), 749-758. https://doi.org/10.1016/j.jstrokecerebrovasdis.2013.06.036

Oliver-Mcneil, S., \& Artinian, N. T. (2002). Women's perceptions of personal cardiovascular risk and their risk-reducing behaviors. Am J Crit Care, 11(3), 221-227.

Scuteri, A., Najjar, S. S., Orru, M., Albai, G., Strait, J., Tarasov, K. V., . . Lakatta, E. G. (2009). Age- and gender-specific awareness, treatment, and control of cardiovascular risk factors and subclinical vascular lesions in a founder population: the SardiNIA Study. Nutr Metab Cardiovasc Dis, 19(8), 532-541. https://doi.org/10.1016/j.numecd.2008.11.004

Snider, E. L. (1980). Awareness and use of health services by the elderly. Med Care, 18(12), 1177-1182. https://doi.org/10.1097/00005650-198012000-00003

Valentín Fuster, B. B. K. (2010). Promoting Cardiovascular Health in the Developing World. Washington, D.C.: The National Academies Press.

Yarger, J., Decker, M. J., Campa, M. I., \& Brindis, C. D. (2017). Rural-Urban Differences in Awareness and Use of Family Planning Services Among Adolescent Women in California. J Adolesc Health, 60(4), 395-401. 
https://doi.org/10.1016/j.jadohealth.2016.10.016

\section{Copyrights}

Copyright for this article is retained by the author(s), with first publication rights granted to the journal.

This is an open-access article distributed under the terms and conditions of the Creative Commons Attribution license (http://creativecommons.org/licenses/by/4.0/). 